\title{
Who Are We Listening to? The Inclusion of Other-than-human Participants in Design
}

\author{
Rodrigo dos Santos \\ rodrigo.dossantos@ubc.ca \\ School of Information \\ University of British Columbia \\ Saguna Shankar \\ saguna@mail.ubc.ca \\ School of Information \\ University of British Columbia
}

\author{
Michelle Kaczmarek \\ michelle.kaczmarek@ubc.ca \\ School of Information \\ University of British Columbia \\ Lisa P. Nathan \\ lisa.nathan@ubc.ca \\ School of Information \\ University of British Columbia
}

\begin{abstract}
Designers' considerations of whom to include as a participant in design research continue to broaden, listening to individuals and communities previously unheard. Some even argue that other-thanhuman entities should be recognized as a type of participant, advocating for non-humans to have a voice in the design process. Through this paper we contribute to this conversation, arguing for a remembering of how to attend to our interactions with diverse forms of life. We refer to these entities as 'pervasive peripheral participants', drawing on early scholarship of Jean Lave and Etienne Wenger. We use this provocative phrase deliberately, to prompt us to consider how we learn with and through these relationships. Non-human, peripheral participants are ubiquitous in all aspects of life, and may inspire designers throughout their project's lifetime, from the environments in which they work, to the resources they use. These participants implicate and are implicated through design. While we recognize that the inclusion of pervasive peripheral participants in design processes is a challenging step to take, this paper holds up scholarly contributions which offer insights to those willing to join this work. We look to projects that do not limit participation in design to human-centred perspectives. These projects offer examples of how to engage with other-than-human ways of being, responding to Daniel Heath Justice's call to "imagine otherwise" (danielheathjustice.com). Learning from these approaches, we imagine how we might attend to relations with otherthan-humans through relinquishing control, fostering collaboration and relationality, practicing reciprocal acts of care, and valuing other temporalities. In doing so, we envision a future when interaction design practice welcomes a broader array of participation, creating space for more ethical and diverse worlds.
\end{abstract}

\section{KEYWORDS}

participatory design, interaction design, relationality, other-thanhuman participation

Permission to make digital or hard copies of part or all of this work for personal or classroom use is granted without fee provided that copies are not made or distributed for profit or commercial advantage and that copies bear this notice and the full citation on the first page. Copyrights for third-party components of this work must be honored. For all other uses, contact the owner/author(s).

LIMITS '21, fune 14-15, 2021,

(c) 2021 Copyright held by the owner/author(s).

\section{Reference Format:}

Rodrigo dos Santos, Michelle Kaczmarek, Saguna Shankar, and Lisa P. Nathan. 2021. Who Are We Listening to? The Inclusion of Other-than-human Participants in Design. In LIMITS '21: Workshop on Computing within Limits, fune 14-15, 2021.

\section{INTRODUCTION}

Fostering relationships with human beings who are directly or indirectly implicated in design processes is a defining move within participatory design (PD) scholarship. To date, less attention has been given to the unfamiliar voices of the more-than- or other-thanhuman. Indeed, humanity's continued attempts to manifest control over the Earth's processes and the ever-increasing demands for faster growth and production conflict with recent gestures towards building collaborative worlds [2, 12, 25, 40, and others]. In response to these compelling discussions about the values of building collaborative worlds to better respond to daunting crises, inquiries into whom (or what) should be considered participants, or co-designers, are of increasing importance.

Within PD, human groupings identified as related to a design research project are often positioned as participants; less attention is given to those individuals and groups who, as yet, have not been fully recognized as directly influencing the design processes, decisions, and outcomes. These are individuals and groups whose activities, practices, and positionalities can influence the projected outcome, but, for some reason, have not been considered during the design project. Examples include overlooked members of a community of practice, or community members whose interests, appreciations, influences, and representations of the project might unsettle dominant interests (as discussed by Costanza-Chock [9]).

Scholars of situated learning, Jean Lave and Etienne Wenger coined the term legitimate peripheral participation to acknowledge the way apprentices, or individuals newly integrated into established communities of practice, move to a more central position over time [26]. The authors of this paper question the idea of central, as it assumes a singular position from which all participation is evaluated. Rather, we consider "multiple, varied, more- or lessengaged and inclusive ways of being located in the fields of participation ...[and] do justice to the diversity of relations involved in varied forms of community membership" [26, pp. 35-6]. Within such dynamics, designers-oftentimes in collaboration with and with the support from a few powerful members of a community 
of practice-extract, collect and distill the information, time, matter, and space they (we) need with few or no intentions to produce community "ownership" or "accountability and control" [9, pp. 90-1]. This oppressive dynamic can be observed in design processes (participatory or not), as well as associated learnings and outcomes.

If challenging the power dynamics in PD would contribute to making design a more just practice, leaving some individuals and groups aside contradicts design justice practitioners' main principles [33]. Instead, design justice practitioners propose that participants should always be involved in the making of their own "thing," an approach that is also shared by feminist and postcolonial scholars [1]. Lave and Wenger see participation as democratic action located in the "social world" [26, p. 36], and based on "situated negotiation of meaning, ...[in which] persons, actions, and the world[s] are implicated in all thought, speech, knowing and learning" [26, pp. 51-2]. From this relational view of participation, people can both define and be defined by the structural forces that are part of their lives. While building reciprocal relationships, designers are challenged to consider how diverse groups will benefit from their participation, peripheral or not, and what implications design practices would have on the agencies, worlds, and activities of these communities.

Through this paper we argue that accepting that nonhumans participate in design is a step towards more democratic, just, and inclusive design. Architecture and urban design scholar Louis Rice argues that visibility and representation play an important role in participatory design. For Rice, "making the invisible more visible would be a desirable mechanism through which to make the participatory design process more democratic" [37, p. 253]. Lack of awareness of the presence of those who may have "something to say" about the design project, those who might influence, as well as be influenced by someone else's argumentations and deliberations, does not facilitate participation. In addition to recognizing the importance of integrating oft-ignored human groups in design processes, we join scholars arguing that other-than-human beings [e.g., 25] offer contributions from their body of knowledge that can inform design practice $[12,28]$. Design scholar Laura Forlano advocates for decentering the human in design practices in order to make it more inclusive for the complexities that collaboration can evoke. For Forlano, design should "find ways to move beyond human needs and the human experience of the world, particularly in light of environmental and economic crisis" [15, p. 53]. She develops her argument on the importance of rethinking the design of socio-technical structures, components that shape the relationship between people and place. However, we still need to give attention to how the ecological environments where design takes place-the natural elements used during, or as outcome of the research process-would be involved in the design process. Despite a long history of humanity learning with and from non-humans and other-than humans, this past has been at best ignored and often ridiculed by those eager to position themselves as "scientific", "sophisticated", "cutting-edge", and "advanced". Ecological entities are typically unrecognized when it comes to participatory design. Yet, along with misrepresented human groups, they are some of the most influential and implicated participants of design projects.
In a recent $\mathrm{BBC}$ Crowd Science podcast episode, "Do animals use medicine?" Jagatia \& Galloway remind listeners of humanity's long history of learning how to heal ourselves by attending to the ways animals and insects use "medicines" from our shared environments [22]. Towards the end of the episode, western-trained scientists acknowledge the long-standing practice of humans learning from our other-than-human neighbors, animals, insects, plants, etc., attending to others through careful observation and reflection (as do Kimmerer, Tsing, Haraway and so many other eloquent scholars). The costs of losing that ability to listen are demonstrated in the Crowd Science program through the story of beekeepers carefully selecting out honeybees who lined their nests with a gummy substance that beekeepers found sticky and annoying. Over multiple generations of bees, these keepers successfully bred the humaninconvenient practice out of their hives. Today, beekeepers recognize that this sticky practice is crucial in preventing unwanted organisms from growing in the hives. Now honeybee populations are plummeting, in part due to their loss of this practice. However, rather than spending more time elaborating on the costs of dominant practices that fail to attend to the lives of other beings, this paper will focus on opportunities designers have to "imagine otherwise" [23].

In this article, we refer to human-centred artefacts, systems, and infrastructures as nonhuman. That is, everything that humans create, and therefore that embodies a form of human knowledge. We refer to as other-than-human beings who are not human, such as birds, insects, and plants, but also wind, rocks, soil, water, lakes, mountains, forests, etc. [25]. As the list of knowledgeable entities grow, it is important to acknowledge that as humans, we are limited to our own experiences, positionalities, and perspectives. To honour the often unheard, other-than-human influences in design practice, we make humble attempts to adopt the "grammar of animacy" [25, p. 55] in this text, recognizing the life of other-thanhuman, pervasive peripheral participants, and the importance they have in design processes. For that, we consider human practices as an integral part of, and in constant conversation with nature. "Nonhumans [and other-than-humans] participate in design conversations by telling humans messages and information" [37, p. 243], as dry soil in a garden communicates it might need watering [34], and a locked washroom door might communicate "come back later". In conversation, speakers and listeners have their own means to express, hear, and interpret the stories they have to share [38].

Air, light, water, and other living beings might be taken for granted actors in design projects, especially when driven by disciplines such as information science and interaction design. These pervasive peripheral participants are overlooked in market-oriented design processes (e.g., Design Thinking), instead of acknowledged as co-designers in their fully expressive form. Rather than resources for extraction and consumption, natural elements might otherwise be seen as participants with whom designers should collaborate in reciprocal relationships, therefore extending the design justice ethos to the other-than-human scope and opening potential possibilities for environmental justice. But how can designers and other peripheral participants co-create in reciprocal terms, caring for each other? This paper responds to this question by considering past LIMITS workshop contributions in which collaborations between humans and other-than-human pervasive peripheral participants 
are enacted. The authors of these earlier papers describe not only their learnings in interacting directly or indirectly with other-thanhumans, but how they reciprocate or give back, through their own means and gifts [25], to these participants. Some of these learnings and forms of exchange are reinforced here, and articulated around orientations that honour other-than-human pervasive peripheral participation in design.

\section{OTHER-THAN-HUMANS WITHIN LIMITS}

Addressing concerns of the HCI community towards the limits of computing must start from our own practice [24]. The following examples from previous contributions to the LIMITS workshop are gestures that broaden the scope of who may be considered as participants in design, and enrich interaction design practice.

In the article Out of control: Reframing sustainable HCI using permaculture, Szu-Yu (Cyn) Liu, Shaowen Bardzell, and Jeffrey Bardzell "argue that permaculture provides an alternative model that emphasizes in the metaphor of cooperation [between human and otherthan-humans]" [28, p. 2]. For these authors, the HCI community often makes use of persuasion to work on aspects of human individuals' lives that are considered to be unsustainable. HCI designers whose work relies on behaviour-change mechanisms risk perpetuating the idea that, in information technology disciplines, we should have the power to establish, standardize, "control and correct" how human beings might or might not behave. Liu et al. conducted ethnographic field work in tea farms in Pinglin and in the rice fields of Yuanshan township, both in rural areas of Taiwan. The former town has partnerships with governmental, research and not-for-profit institutions to strengthen traditional tea cultivation practices, in alignment with "the importance of embedding sustainable design interventions in the context of political relationship and social structure" [28, pp. 1-2], rather than focusing on individuals. In the Yuanshan township, even though it is a traditional region of rice cultivation, the area is also known for conducting experimental farming practices. Many of these practices focus on the idea of "working with nature" [28, p. 3]. For the authors, "working with nature means 'providing care', which requires humans to engage in appropriate actions in order to maintain, continue, and repair the interdependent world" [28, p. 5, emphasis in the original]. In their ethnographic work, the authors detail how a series of individuals involved in the small-scale farming in these regions practice "collaboration and care" [28, p. 3]. For example, they mention that two of Taiwan's famous teas (oriental beauty and honey scented tea) are a result of "tea farmers having an effective relationship with non-human actors (in this case, bugs) in tea cultivation" [28, p. 3]. Also, the authors explain that, in alignment with permaculture ethics, these farmers "return their surplus" [28, p. 4] to nature, giving back what they will not use or need to the soil, or to the birds to eat, for example. These individuals, even though engaged in farming related practices, are also filmmakers, designers, architects, lawyers, and engineers whom, in many cases, integrated the practice of caring for the community, the land, and other beings into their professional roles. Liu and colleagues suggest that working with nature is a type of "partnership" (as also seen in $[2,14]$ ) through which reciprocal acts of care can be incorporated and enacted through HCI projects.
Such human and other-than-human partnerships can be observed in the article The Lions' Gate: Towards a permaculture-inspired blended space. Callum Egan, Richard Thompson, and Andrew O'Dowd view the ongoing climate crisis as an outcome of modern "humanity's disconnect from the natural world" $[10$, p. 1]. They present what they call a "radical framework" that is drawn from permaculture principles in order to "address the limits to computing" [10, p. 1]. They do so by exploring "blended spaces perspectives to permaculture, university campuses and digital media" [10, p. 1]. Differently than Liu et al. [28], the authors advocate for an action-based approach to address the climate crisis, by "transforming [human] attitudes and influencing behaviours" [10, p. 7]. In this sense, Egan and colleagues nurtured a permaculture-inspired garden called Lions' Gate, and envisioned analog and digital artefacts that support and mediate how people will navigate within, and interact with the garden. The garden is located in "an urban university campus in Edinburgh, Scotland, ....approximately 110 metres above sea-level, and sat upon an enormous chunk of basalt" [10, p. 3]. While the authors acknowledge the location and characteristics of the physical space where the Lions' Gate is situated, there is opportunity to further acknowledge the participation of other-than-humans in the design of the garden itself. For instance, by questioning more directly how the chunk of basalt participated in the design of the garden, the authors might identify that such a massive, earthly being may contribute not only to the designers' understanding of how the garden is developed, but also to how people may feel welcome to navigate, and interact with the garden (not to mention the interactions of the garden's herbs and vegetables with that rock). Similar questioning would apply for assessing the influence that food forests, ponds, and enriching soil with compost and manure may have for a given design and its pervasive peripheral participants. Besides the garden itself, Egan and colleagues co-designed the "Interactive Platonic Storytelling Chair," which consists of an interactive chair intended to "bring teaching back into natural surroundings" [10, p. 6], as Plato used to teach, and as many Indigenous peoples continue to teach today. The chair was designed in collaboration between interaction designers, engineers, carpenters, and oak trees. While connected to a network, the chair interacts with garden goers by informing them about what's going on in the garden, or suggesting new environmental sustainability-related additions to the library of the university where the garden is situated. Even though this interactive artefact carries a hint of solutionism to a context that is too complex to be 'tackled' with a single approach [24, 40], the speculative component of this artefact incites conversations that may foster additional collaborations and learnings between humans and the garden.

Other blended spaces take place in the article Experimenting with Novel Forms of Computing: The case of the Swedish Citizen Observatory for Water Quality Conservation. Teresa Cerratto Pargman, Somya Joshi, and Uta Wehn describe the co-design of the VattenFokus citizen observatory ( $\mathrm{CO}$ ), involving the participation of different human stakeholders (e.g., citizens, policymakers, scientists) in this process [7]. The VattenFokus $\mathrm{CO}$ is a socio-technical platform (a human and nonhuman hybrid tool) intended to address water quality and management in Sweden, and to identify the different perspectives various actors may take to this end. Cerratto Pargman and colleagues view this platform as a means to "develop 
new relationships" [7, p. 2] between members of the community, rather than a tool through which the stakeholders may work together. In this article, they advocate for "relational models in $\mathrm{HCI}$ " [7, p. 2], models that support local communities by focusing on their "interpersonal relations," [7, p. 3] rather than on the digital technology itself. "Relational models" can be mediated by sociotechnical infrastructures such as networked COs, for "mobilizing collective action" and enabling "gathering[s]" where the "relationships and trust between actors" [7, p. 3] can be fostered and "carr[ied] forward independently beyond the [project] life-cycle" [7, p. 3]. The authors argue that "[f]or sustainability of initiatives that have at their heart designing socio-technical systems for a future of limits and scarcity," such as the water management COs, it is imperative "to not lock-into prescriptive language, methodologies, technical tools or decision making hierarchies, that would exclude segments of stakeholders, thereby allowing for a more fluid arrangement of adaptive governance of socio-ecological systems" [7, p. 8]. Even though it is not stated in the article, it is crystal clear-or water clear-the role that water played in the design of such a system, as it is also clear the influence that the Lions' Gate permaculture garden had on the interactive artefact that Egan and colleagues discuss in their paper [10]. Treated as a commons, water is not only a shared resource, it is a pervasive peripheral participant that deserves attention and care from all. Treated as an integral part of who we are and what we can become, water is a teacher, offering guidance on our way of being, our actions, and our relationships with other humans and other-than-humans.

Through our discussion of the above examples we identify practices through which people engage with the things they use, the humans and communities they care for, as well as with the land, plants, and other nature elements they tend. These are calls to "reframe the sustainable HCI practice" [28], create "radical frameworks" [10], and build "relational models in HCI" [7]. All involved in these design research examples [7, 10, 28] hold knowledges that were nurtured through conversation and interactions between humans, non-humans, and other-than-human entities.

In the next section of this paper, we interweave these contributions to suggest that through design practice, humans have opportunities to engage-and potentially make sense of-the different beings that influence humanity's social, ecological and political processes. Designers and researchers may have insights on how these structures have been put together, what they could have been, and what could be done to make their world a better place, not only for themselves, but for the livelihood of human and other-than-human communities.

\section{ATTENDING TO INTERACTIONS WITH OTHER-THAN-HUMANS}

In a 2018 pictorial paper, Szu-Yu (Cyn) Liu, Jeffrey Bardzell, and Shaowen Bardzell investigated human and non-human interactions and interdependence through the influence of natureculture [27]. They use photography to depict moments in which such communication occurs (e.g., weeds reclaiming space in an abandoned stairway, and architecture that invites snowflakes and outdoor views in). For Liu and colleagues, these examples communicate how the
HCI community might benefit from attending to the intimate relationships that can happen through the interaction of human and other-than-humans. As another example, Alex Morss describes how botanists supported by their peers, chalk, and other people in urban communities engage in graffiti interventions-and even break the law-to identify weeds, herbs, trees, and other plants that populate urban environments across different locations in Europe, [32]. Such action-based movements may alert humans wrapped up in the mundanity of their everyday life journeys, not attending to other beings, to the presence of pervasive peripheral participants, who are attempting to reclaim their space between pavement fissures, concrete walls and narrow garden strips. Naming these plants may work as a form of introduction or greeting. As a speculative exploration of multispecies worlding, interaction design scholar Michelle Westerlaken sought to extend awareness of these interactions through artistic modes of communication "towards less language-oriented forms of thinking-with multispecies encounters" [44, p. 139]. Liu and colleagues' photographic sensibility, the botanists' graffiti described by Morss, as well as Westerlaken's illustrations, are examples of interventions that bring awareness to other-thanhumans' presence and influence in our lives.

Visibility and representation play an important role in participatory design. Alexis Shotwell notes that "[n]aming and noticing might be a way to care humanly" [40, p. 99]. Being aware and caring for the presence of those who have something to say in the design process facilitates the participation of those who might influence and be influenced by someone else's arguments and deliberations. Questions remain open about how to enable democratic design processes between humans and other-than-humans who embody different ways of being. In such processes, participants may be unsure of how to reach consensus or even identify disagreements. "During the participatory design process, there are a series of actions that lead to the building of new networks and, equally importantly, the cutting of ties with other networks" [37, p. 242]. Visibility, representation and awareness might not be enough to attend to other-than-humans' worlds.

By acknowledging the presence of "weeds" in the environment, municipal authorities may feel inclined to take them out. The category of weed, an undesirable plant in a particular location, may represent a challenge to some people's desire to keep things neat and under control. As Alexis Shotwell writes, "purism is a de-collectivizing, de-mobilizing, paradoxical politics of despair" [40, p. 9]. We argue that 'relinquishing control,' 'fostering collaboration and relationality, ' practicing acts of care,' and 'valuing alternative temporalities' are some of the orientations designers within and beyond the HCI community should consider, as they move to incorporate pluralistic understandings in participatory design practices. These orientations are not new, they are already fostered by many whose scholarship encourages interdependence [12], co-constitution of beings [40], reciprocal care [25], and inclusivity and justice [9, 17, 18]. Yet, "[w]hat follows ethically from understanding ourselves to be relationally constituted?" [40, p. 116]-this is work yet to be done.

As designers, or simply as human beings, many of us still fail to notice and recognize the presence of other-than-human beings in our everyday journeys and practices. The following orientations, drawn from aligned scholarship, strive to broaden design considerations as we attempt to imagine otherwise [23], recognizing the 
limitations of dominant approaches that have contributed to our growing climate and climate justice crises. We question humanity's pervasive centrality in design processes, and shift our perspective to reposition ourselves as co-participants with other-thanhumans, together in pervasive peripherality.

\subsection{Relinquishing Control}

In their critique of the limits of farming, Lindsay Barnieri, Sonya Ahamed and Sam Bliss state that for modern agriculture, "manipulating living beings, their genetics, and entire ecosystems to produce food, has always been a technological feat" [3, p. 70]. For them, the development of precision farming technologies means that small farmers have less control over what is produced and how. Farming has become a centralized activity that is run by global agro-businesses that retain the patent of modified seeds, and require engineered fertilizers, processes and machinery to be productive. The more farming becomes a specialized activity controlled by few, the more people get pushed away from an ancient way of nurturing and being nurtured. Liu and colleagues suggest that "the control model (one that maximizes labor efficiency) puts humans outside of ecology, managing it as if it were an object under human management. In contrast, the permaculture model (one that maintains, repairs, or improves the natural conditions we are living in) places humans into the ecology as actors but not controllers" [28, p. 5]. Permaculture is one example of an approach to relinquishing (the illusions of) human control in farming, as it "provides an alternative model that emphasizes on the metaphor of cooperation (e.g., human as collaborator)" [28, p. 2]. The platform designed by Cerratto Pargman and colleagues embraces "relational models" as it allows for the construction of mechanisms of self-governance [7]. It deconstructs top-down hierarchies and empowers different stakeholders to have a voice in the water management of their community.

When organic shapes of nature can express who they are and what they need, they co-design along with human-built environments. Design Justice scholar Sasha Costanza-Chock claims that in order for design work to be just, it must ensure that all involved in the design process are valued and rewarded as co-creators, not only as resources to be extracted, providers of information, time, matter, and space [9]. In building up reciprocal relationships, design must consider how direct and peripheral participants share control and receive different benefits from their participation.

\subsection{Fostering Collaboration and Relationality}

Anthropologist Arturo Escobar challenges us to consider, "What would it mean to develop a personal and collective practice of interbeing?" [12, p. 103]. Fostering collaborative practice in design entails not only welcoming direct stakeholders into design projects, but also giving peripheral participants a central position in the process. Or, in the context of ecological environment, this means decentering humans by recognizing the importance of other-thanhumans in our everyday choices and decisions. Michelle Westerlaken elaborates that it requires training to engage with other-thanhuman worlds, and a turning point in such training is the recognition that not only us, humans, respond to the influences of other beings, they too respond to our actions [44]. By focusing on human individuals, we neglect the implication that design has on various life forms [28]. "Recognizing the interdependency of all forms of life, ...decentres human ethical subjectivity by not considering humans as masters nor even as protectors of, but as part of Earth's living beings" [36, p. 152]. As seen in Liu et al. [28], things, humans (from different cultures and upbringing), and other-than-human entities co-participate in the construction of living environments by continuously interacting with and learning from each other.

Indigenous scholar Robin Wall Kimmerer describes the collaboration between a member of the Pigeon family of Potawatomi basket makers and the black ash trees, from whom the Pigeon family harvests log rings used in their baskets. In Kimmerer's telling, care involves, but is not limited to, finding the right black ash tree in the woods, one that seems "ready to be a basket" [25, p. 143], and engaging in a type of dialogical inquiry to determine whether the tree grants permission to be made into baskets. Kimmerer explains the perspective of the harvester when they encounter and question a tree: "Traditional harvesters recognize the individuality of each tree as a person, a nonhuman forest person. Trees are not taken, but requested. Respectfully, the cutter explains his purpose and the tree is asked permission to harvest. Sometimes the answer is no. It might be a cue in the surroundings - a vireo nest in the branches, or the bark's adamant resistance to the questioning knife-that suggests a tree is not willing, or it might be the ineffable knowing that turns him away" [25, p. 144]. Human and other-than-human communication may lie beyond human interpretation.

Alexis Shotwell describes "open normativities" as the "collectively crafted ways of being that shape subjectivities oriented toward widespread flourishing." [40, p. 139]. Open normativities decentre the human and welcome pluriversal forms of expression while breaking up dominant patterns of participation. In the projects developed in the Lions' Gate garden and described by providing new meaning to a physical space (the university campus), by augmenting how different beings interact with a human-other-thanhuman relational tool (permaculture) and a digital technology tool (augmented reality game and storytelling chair), Egan et al. [10] brought together not only interaction designers, engineers, carpenters, and ancient oak tree[s] in the form of reclaimed wood, but basalt, soil, and all other species that compose the garden and inspire each other.

The activities of composing and composting may be helpful ways of thinking about collaboration with more-than-humans [21], as we, together, "continuously make, share, break and give form to [many] worlds" [44, p. 144]. In addition to Donna Haraway's compos(t)ing as a metaphor of methods for working with the contributions of one another as beings [21], thinking about the return and regeneration of existing energy that already circulates could challenge assumptions that humans and machines are dominant sources of agency, energy, and creation.

\subsection{Practicing Reciprocal Acts of Care}

Egan et al. argue that permaculture is the "action-oriented sustainable design framework that is radical, practical, self-empowering and works at all scales of development from the self to the many" $[10$, p. 2], embracing the concept of relational care. This ethos is also observed in earlier ethnographic field work conducted by Liu 
and colleagues [28]. They explain, for instance, that the farmers in Pinglin deliberately decide not to exhaust what the plants yield, leaving it to nature to decide what she will do with them.

Care can be engaged and experienced as a mode of collaboration between beings. Care may be oriented towards many ends, as various as healing, intervening in harms, strengthening quality of life, and managing as well as possible with shifting disturbances or uncertainties. As a process, care happens when we are called on to recognize and act upon dynamics of conditions-whether of the health of an ecosystem, a species, a human, a collective, or another entity. Attuning to vital signs of wellbeing and making continual adjustments is care, and can also be interpreted as redesign.

The feminist tradition of care ethics points out the moral, political, and uneven nature of caregiving work performed between humans $[8,41]$. When it comes to growing food, Vandana Shiva notes that "the creativity, innovation, and decision-making power of women (who still produce 80 percent of the world's food) has significantly driven the world's biodiversity. The majority of the eighty thousand plant species that humans have cultivated have emerged from the self-organizing, living energies of women. In other words, if we are going to redefine wildness, we have to simultaneously redefine humans as cocreators of wealth with nature. We both rely on and cocreate wildness when our living energies work with those of the earth" [39, p. 231]. While the work of care is often classed, raced, and gendered, caring can also be understood as distributed amongst nonhuman and human assemblages.

In their studies of caring practices on farms, in homes, and at medical clinics, Annemarie Mol, Ingunn Moser, and Jeanette Pols remind us that caring is not inherently human [31]. As they note, "Caring practices, to start there, include technologies: from thermometers and oxygen masks to laboratory tests and video cameras. If they happen to be helpful then they are all welcome. At the same time, engaging in care is not an innate human capacity or something everyone learns early on by imitating their mother. It is infused with experience and expertise and depends on subtle skills that may be adapted and improved along the way when they are attended to and when there is room for experimentation" [31, p. 14]. The work of care involves the ability to develop expertise, enact skills, and to tinker.

With the understanding that "practices of caring can be cultivated" [41, p. 8], what are researchers' and designers' responsibilities? "[I]f care is a form of relationship it also 'creates' relationality. In that sense, as permaculture care ethics consider, humans are not the only ones caring 'for' the earth and its beings-we are 'in' relations of mutual care. Many nonhuman agencies are taking care of many human needs, as much as humans have their own tasks in the maintenance of the web of caring” [36, p. 164, emphasis in the original].

Strengthening relationships is necessary ongoing care work for collective survivance of living species and spaces. This type of care work is connective and continuing. And yet, within the span of a mere moment in geological time, restorative interactions may still be adapted or prefigured in research and design.

\subsection{Valuing Alternative Temporalities}

Design is dominantly structured by human temporalities in both its methods and its outlook. HCI scholars have attended to the influence of modernist, Western, and short-term framings of time and the future in computing research and design, and called for the inclusion of more diverse temporalities [e.g., 4, 5]. And yet, what Genevieve Bell and Paul Dourish term the "proximate future"aligned with human consumption patterns and lifespans, oriented towards technological breakthroughs "right around the corner"remains pervasive [4, p. 134]. In his exploration of the "underland"the rarely seen terrains under our feet-nature writer Robert MacFarlane notes that the roles and influence of our environment can be hidden by our human-centred timescales, when he observes, " $\mathrm{t}]$ he underland is vital to the material structures of contemporary existence, as well as to our memories, myths, and metaphors. It is a terrain with which we daily reckon and by which we are daily shaped. Yet we are disinclined to recognize the underland's presence in our lives. ... Our 'flat perspectives' feel increasingly inadequate to the deep worlds we inhabit, and to the deep time legacies we are leaving" [30]. Through his engagements, MacFarlane sees the world, and its complex interconnectedness, through the vast timescales of the ancient geology in which he is submerged, "measured in units that humble the human instant: epochs and aeons, instead of minutes and years. Deep time is kept by stone, ice, stalactites, seabed sediments and the drift of tectonic plates. Deep time opens into the future as well as the past" [30]. Attending to the temporalities of other-than-humans can help us to appreciate this interconnection and open space for pervasive peripheral participation that may not be visible from within the confines of humancentred temporal frames.

Terms such as 'rapid prototyping,' 'agile methodologies,' 'get things done,' 'fail fast fail often,' as well as the pervasive 'quick and dirty' are just some examples that point to the recurrent incentives for speed in ways we define and approach problems, particularly in HCI. Given the urgency for actions that address environmental disruptions and other ongoing crises, it may seem paradoxical to urge the HCI community to slow down [24]. Some might argue that the purpose of rapid prototyping is to identify points of failure before they are implemented, and that agile methodologies enable iterative rounds of action in which things done in previous sprints can be enhanced and errors corrected as the project moves on. However, what happens quite often in practice is a 'get things done and move on to the next feature the market wants to see implemented.' The quick and dirty methods are then justified and destined to stay implemented as such until further notice. In contrast, Sasha Costanza-Chock offers that, in order to build "more just and sustainable world[s]" [9, p. 219], design processes should be developed slowly. Even though this approach will most likely be questioned, or simply ignored, by the design industry, Costanza-Chock is not the only one who questions effectiveness as a time-based parameter. Barbieri and colleagues suggest that we "embrace inefficiency" to collaborate in a more respectful way with nature, while explaining that, in the context of industrial farming practices and technology, "the more efficiently humans have turned nature into food, the more nature our species has consumed and transformed overall" [3, p. 73]. 
Noticing engagements with other-than-human timescales can bring forward new kinds of questions for design that implicate pervasive peripheral participants. In visiting the site of a soon-to-be nuclear waste repository, buried deep in an extinct volcano, MacFarlane observes, "the timescale of the hazard is such that those responsible for entombing this waste must now face the question of how to communicate its danger to the distant future. This is a risk that will outlast not only the life of its makers but perhaps also the species of its makers. How to mark this site? How to tell whatever beings will come to this desert place that what is kept in this rock sarcophagus is desperately harmful, is not of value, must never be disturbed?" [30, emphasis in the original]. Like the predicament that MacFarlane considers, Friedman and Nathan's multi-lifespan information system design draws attention to the many systemic issues-colonialism, climate change, genocide-that are unlikely to be "solved" within a human lifespan [17]. They argue that these issues require longer-term, flexible and infrastructural approaches that subvert solutionist assumptions "in a field known for cutting edge innovation, where devices over 5 years old are regarded as legacy" [17, p. 2,243]. By calling for HCI scholars to consider design beyond the human lifespan, Friedman and Nathan demonstrate how the temporal limits of dominant technological futures place constraints on the kinds of systems we can imagine, and how humans, non-humans, and other-than-humans may participate in the shaping and reshaping of systems over time [17].

In framing their work through different temporalities, scholars and designers are challenging dominant perceptions that shortterm futures, and the humans that occupy them, are the only ones of relevance to information and technology design. There are undoubtedly challenges in applying different temporal scales. For example, it can be especially challenging to imagine worlds in which we (individually or collectively) are no longer present. In one extreme example, von Mossner has described the "crisis of imagination" of considering the vast scale of the "Anthropocene", including conceptualising the collective agency and experience of humans as a geophysical force [43]. Storytelling and narrative can help to transport us to different, far future worlds, beyond the human lifespan or even current human civilizations. We have much to learn from storytellers of speculative fiction who help us to imagine possibilities for more-than-human futures. In their "Multi-lifespan Envisioning Cards", a recent addition to the "Envisioning Cards" [16], Friedman, Yoo and colleagues inspire designers to "think with a very long time horizon that reaches beyond a single lifespan" [45]. Each card introduces questions and practices which support designers in focusing on, among other things, how the systems they desire may represent and marginalize different stakeholders over time, or ways such systems might "connect directly or indirectly with long term natural cycles" [45]. Multi-lifespans can reach beyond considerations of temporal difference, of sharing and absorbing information, but also different ways humans and other-thanhumans relate with information in different moments of their lives. Acknowledging and respecting that such differences may happen opens up possibilities to relinquish control and make space for unexpected forms of participation and collaboration.

\section{DISCUSSION}

Design scholars Yoko Akama, Ann Light and Takahito Kamihira alert us that "[a]sking whose and what stories are told (and listened to) heightens an acuteness for what participation means" [2, p. 3]. By considering participation from the positionality of nonhuman/other-than-human participants, we are part of movements reorienting the human-centrism of the design disciplines to invite perspectives that are commonly ignored or marginalized by design. We have inquired into relinquishing control, fostering collaboration and relationality, practicing acts of care, and valuing alternative temporalities as modes of attending to interactions with other-than-humans. However, our perspective will always be partial and situated. Expecting that other-than-humans (plants, rocks, water) consent to and participate in a design process is paradoxical and can perpetuate human-centrism [2] and "humanist chauvinism" [35, p. 100]. How people view themselves in continuous conversations (interactions) with each other, things, and as constituents of nature is subject to multiple interpretations. Designers and researchers may wonder what the natural worlds may "say" about their work. As humans, we are limited in our ways of knowing by the limitations of our senses and sense-making capacities and from our socio-technical perspective. HCI community members who wish to limit humanity's disruption of our ecological environments, also recognize human limits as they reorient their own practice, moving away from ways of doing design that reinforce destructive structures of power. Members of these communities can attend to pluriversal lenses that foster interdependence, care, and inclusivity [12]. Attending to natural entities aims to do justice to pervasive peripheral participants who are commonly unheard, excluded from pseudo-democratic design processes and practice.

Even though Egan et al. do not directly acknowledge the participation of other-than-humans, who influence the projects they engage with in the Lions' Gate garden, they recognize that " $t \mathrm{t}] \mathrm{he}$ fictions that humans attach to non-human actors can be incredibly useful when considering how we can be more sustainable in our approach to design" [10, p. 6]. In this case, the non-human actors are the "Interactive Platonic Storytelling Chair," and any other artefacts with whom humans and other-than-humans interact. Design stories and subjectivities are not only interpreted by individuals-nor in specific situations-designers mean to address with their work. Liu et al. [27, 28] and Cerratto Pargman et al. [7] show that there are implications of our design decisions that lay beyond the human realm. Designed artefacts, systems, and services implicate, but are also implicated by, their surroundings and diverse lifeforms, also observed in Egan et al. [10].

While investigating "design trade-offs," Gerhard Fischer challenges the design community to go beyond questionings of how they "can do it" toward ethical questionings of whether they "should do it" [13, p. 2]. We extend these inquiries beyond questioning whether an innovative interface, product, service, or technology should be designed. As designers and researchers, we can question to whom we should listen before, during, and after a project, who might influence and be implicated by such a project, and what we should have in mind while working with nonhuman entities.

It is true that there are limits to our argument. We do not speak the same language or think with the same logics as the myriad 
participants in our design projects. Kimmerer reminds us that conversations with plants happen in a different language. We may ask them questions, but "they won't answer verbally" [25, p. 158]. They respond to our gestures [19] also through their own gestures and behaviours. Akin to Anna Tsing's experiments in the "arts of noticing," designers and researchers can learn different means of interpretation [42, p. 37]. "Plants answer questions by the way they live, by their response to change; you just need to learn how to ask" [25, p. 158].

Human individuals and communities, human-made things and living beings, share experiences. Through their own ways of knowing, they inform and are informed by design practices. Even though humans and other-than-humans collaborate in continuous interactions as constituent parts of nature, humans often feel as if they work in isolation from other life forms. Conceptualizing humans as set apart from-rather than inextricably embedded within-nature can legitimize power abuses over other-than-human worlds. Even though some in the design community attend to collaborations with other-than-humans, not only 'listening to what they have to say', but also inviting them to directly or indirectly participate in design processes [e.g., 6, 7, 10, 28, 44], many in design scholarship and industries have much to learn from environmental justice advocates, artists, storytellers, and story keepers who strive to honour ways of knowing that are not human [e.g., 11, 20, 23, 25, 29]. 'Relinquishing control,' 'fostering collaboration and relationality' 'practicing acts of care,' and 'valuing alternative temporalities' may contribute to ways design and-other world making practices-can attend to other-than-human interactions.

\section{CONCLUSION}

Rather than offering a ground-breaking innovation or concept, this paper contributes a re-membering. We remind ourselves that otherthan-human entities are already participants in the design process, directly and indirectly influencing and being influenced by humandriven interventions. Why would we want to break the ground, anyway?

Other-than-human entities are beyond sources of matter, setting, or inspiration for human extraction. We highlight the importance of recognizing, naming and including pervasive peripheral participants in research and design processes. We invite otherthan-humans to design conversations, and aim to collaborate with them to make design a more equitable and radically democratic practice. In relations, we have the capacity to develop reciprocal acts of care that may extend beyond each other's temporality. In this process, social and environmental justice are co-constituted, opening up spaces where diverse worlds can flourish.

\section{ACKNOWLEDGMENTS}

We are grateful to the many humans and other-than-humans who have inspired, supported and challenged our thinking for this paper. In particular, we would like to thank and acknowledge the LIMITS scholarship that precedes, accompanies, and informs our work, and our reviewers for their helpful comments. Among our pervasive peripheral participants, we owe much to the plants and critters that live with us on the traditional, ancestral and unceded territory of the Səlilwatał (Tsleil-Waututh), Skwxwú7mesh (Squamish), and $x^{w}$ mə $\theta k^{w}$ əy่วm (Musqueam) Peoples.

\section{REFERENCES}

[1] Shana Agid and Elizabeth Chin. 2019. Making and negotiating value: design and collaboration with community led groups. CoDesign 15, 1 (2019), 75-89.

[2] Yoko Akama, Ann Light, and Takahito Kamihira. 2020. Expanding Participation to Design with More-Than-Human Concerns. In Proceedings of the 16th Participatory Design Conference 2020 - Participation(s) Otherwise - Volume 1 (Manizales, Colombia) (PDC '20). Association for Computing Machinery, New York, NY, USA, 1-11. https://doi.org/10.1145/3385010.3385016

[3] Lindsay Barbieri, Sonya Ahamed, and Sam Bliss. 2019. Farming within limits. Interactions 26, 5 (2019), 70-73.

[4] Genevieve Bell and Paul Dourish. 2007. Yesterday's tomorrows: notes on ubiquitous computing's dominant vision. Personal and ubiquitous computing 11, 2 (2007), 133-143.

[5] Nicola J Bidwell, Thomas Reitmaier, Carlos Rey-Moreno, Zukile Roro, Masbulele Jay Siya, and Bongiwe Dlutu. 2013. Timely relations in rural Africa. In Proceedings of the 12th International Conference on Social Implications of Computers in Developing Countries. 92-106.

[6] Zach Camozzi. 2019. Earthbond Prototyping, a Method for Designers to Deepen Connections to Nature. In Design and Nature: A Partnership, Kate Fletcher, Louise St. Pierre, and Mathilda Tham (Eds.). Routledge, New York, NY, 146-152.

[7] Teresa Cerratto Pargman, Somya Joshi, and Uta Wehn. 2019. Experimenting with Novel Forms of Computing: The Case of the Swedish Citizen Observatory for Water Quality Conservation. In Proceedings of the Fifth Workshop on Computing within Limits (Lappeenranta, Finland) (LIMITS '19). Association for Computing Machinery, New York, NY, USA, Article 8, 10 pages. https://doi.org/10.1145/ 3338103.3338111

[8] Andreas Chatzidakis, Jamie Hakim, Jo Littler, Catherine Rottenberg, and Lynne Segal. 2020. From carewashing to radical care: The discursive explosions of care during Covid-19. Feminist Media Studies 20, 6 (2020), 889-895.

[9] Sasha Costanza Chock. 2020. Design justice: Community-led practices to build the worlds we need. The MIT Press, Cambridge, MA.

[10] Callum Egan, Richard Thompson, and Andrew O'Dowd. 2019. The Lions' Gate: Towards a Permaculture-Inspired Blended Space. In Proceedings of the Fifth Workshop on Computing within Limits (Lappeenranta, Finland) (LIMITS '19). Association for Computing Machinery, New York, NY, USA, Article 7, 8 pages. https://doi.org/10.1145/3338103.3338110

[11] Pippa Ehrlich and James Reed. 2020. My Octopus Teacher. Retrieved May 19, 2021 from https://www.netflix.com/ca/title/81045007

[12] Arturo Escobar. 2018. Designs for the pluriverse: Radical interdependence, autonomy, and the making of worlds. Duke University Press, Durham, NC.

[13] Gerhard Fischer. 2018. Identifying and Exploring Design Trade-Offs in HumanCentered Design. In Proceedings of the 2018 International Conference on Advanced Visual Interfaces (Castiglione della Pescaia, Grosseto, Italy) (AVI '18). Association for Computing Machinery, New York, NY, USA, Article 22, 9 pages. https://doi. org $/ 10.1145 / 3206505.3206514$

[14] Kate Fletcher, Louise St. Pierre, and Mathilda Tham (Eds.). 2019. Design and nature: A partnership. Routledge, London, United Kingdom.

[15] Laura Forlano. 2016. Decentering the human in the design of collaborative cities. Design Issues 32, 3 (2016), 42-54.

[16] Batya Friedman, Lisa Nathan, Shaun Kane, and John Lin. 2008. Envisioning Cards.

[17] Batya Friedman and Lisa P. Nathan. 2010. Multi-Lifespan Information System Design: A Research Initiative for the Hci Community. In Proceedings of the SIGCHI Conference on Human Factors in Computing Systems (Atlanta, Georgia, USA) (CHI '10). Association for Computing Machinery, New York, NY, USA, 2243-2246. https://doi.org/10.1145/1753326.1753665

[18] Batya Friedman, Lisa P Nathan, and Daisy Yoo. 2017. Multi-lifespan information system design in support of transitional justice: Evolving situated design principles for the long(er) term. Interacting with Computers 29, 1 (2017), 80-96.

[19] Gesturing Towards Decolonial Futures. n.d.. Introduction to Bayesian Statistics. Retrieved May 19, 2021 from https://decolonialfutures.net

[20] Ross Gay. 2019. The book of delights. Algonquin Books of Chapel Hill, Chapel Hill, NC.

[21] Donna Haraway. 2016. Staying with the trouble: Making kin in the Chthulucene. Duke University Press, Durham, NC.

[22] Anand Jagatia and Rory Galloway. 2021. Do animals use medicine? Retrieved May 19, 2021 from https://www.bbc.co.uk/sounds/play/w3cszv77

[23] Daniel Justice. 2018. Why Indigenous literatures matter. Wilfrid Laurier University Press, Waterloo, Canada.

[24] Michelle Kaczmarek, Saguna Shankar, Rodrigo dos Santos, Eric M. Meyers, and Lisa P. Nathan. 2020. Pushing LIMITS: Envisioning beyond the Artifact. In Proceedings of the 7th International Conference on ICT for Sustainability (Bristol, United Kingdom) (ICT4S2020). Association for Computing Machinery, New 
York, NY, 255-266. https://doi.org/10.1145/3401335.3401367

[25] Robin Kimmerer. 2013. Braiding sweetgrass. Milkweed Editions, Minneapolis, MN.

[26] Jean Lave and Etienne Wenger. 1991. Situated Learning: Legitimate Peripheral Participation. Cambridge University Press, Cambridge, United Kingdom.

[27] Szu-Yu (Cyn) Liu, Jeffrey Bardzell, and Shaowen Bardzell. 2018. Photography as a Design Research Tool into Natureculture. In Proceedings of the 2018 Designing Interactive Systems Conference (Hong Kong, China) (DIS '18). Association for Computing Machinery, New York, NY, 777-789. https://doi.org/10.1145/ 3196709.3196819

[28] Szu-Yu (Cyn) Liu, Shaowen Bardzell, and Jeffrey Bardzell. 2018. Out of Control: Reframing Sustainable HCI Using Permaculture. In Proceedings of the 2018 Workshop on Computing within Limits (Toronto, Canada) (LIMITS '18). Association for Computing Machinery, New York, NY, Article 2, 8 pages. https: //doi.org/10.1145/3232617.3232625

[29] Elizabeth Lo. 2021. Stray. Retrieved May 19, 2021 from https://www.strayfilm.co.uk

[30] Robert Macfarlane. 2020. Underland: A deep time journey. Penguin Books, London, United Kingdom.

[31] Annemarie Mol, Ingunn Moser, and Jeannette Pols. 2010. Care in practice: On tinkering in clinics, homes and farms. transcript Verlag, Bielefeld, Germany.

[32] Alex Morss. 2020. 'Not just weeds': How rebel botanists are using graffiti to name forgotten flora. Retrieved May 1, 2021 from https://www.theguardian.com/environment/2020/may/01/not-just-weedshow-rebel-botanists-are-using-graffiti-to-name-forgotten-flora-aoe

[33] Design Justice Network. 2018. Design Justice Network Principles. Retrieved May 19, 2021 from https://designjustice.org/read-the-principles
[34] William Odom. 2010. "Mate, We Don't Need a Chip to Tell Us the Soil's Dry": Opportunities for Designing Interactive Systems to Support Urban Food Production. In Proceedings of the 8th ACM Conference on Designing Interactive Systems (Aarhus, Denmark) (DIS '10). Association for Computing Machinery, New York, NY, USA, 232-235. https://doi.org/10.1145/1858171.1858211

[35] Hannah Pitt. 2016. An apprenticeship in plant thinking. In Participatory Research in More-than-Human Worlds. Routledge, New York, NY, 106-120.

[36] Maria Puig de la Bellacasa. 2010. Ethical doings in naturecultures. Ethics, Place \& Environment 13, 2 (2010), 151-169.

[37] Louis Rice. 2018. Nonhumans in participatory design. CoDesign 14, 3 (2018), 238-257.

[38] Dylan Robinson. 2020. Hungry listening : resonant theory for indigenous sound studies. University of Minnesota Press, Minneapolis, MN.

[39] Vandana Shiva. 2017. Cultivating the Wild. In Wildness: Relations of people and place, Gavin Van Horn and John Hausdoerffer (Eds.). The University of Chicago Press, Chicago, IL, 229-232.

[40] Alexis Shotwell. 2016. Against purity: Living ethically in compromised times. University of Minnesota Press, Minneapolis, MN.

[41] Joan Tronto. 2013. Caring democracy : markets, equality, and justice. New York University Press, New York, NY.

[42] Anna Tsing. 2015. The mushroom at the end of the world: on the possibility of life in capitalist ruins. Princeton University Press, Princeton, NJ.

[43] Alexa Weik Von Mossner. 2016. Imagining geological agency: Storytelling in the Anthropocene. RCC Perspectives 2 (2016), 83-88

[44] Michelle Westerlaken. 2021. It matters what designs design designs: speculations on multispecies worlding. Global Discourse: An Interdisciplinary fournal of Current Affairs 11, 1-2 (2021), 137-155.

[45] Daisy Yoo, Nicholas Logler, Stephanie Ballard, and Batya Friedman. 2018. Multilifespan Envisioning Cards: Supplementary Set. 